The temporal variation of the tropospheric radiocarbon inventory $N_{\text {trop }}$ is determined by the net exchange fluxes with the ocean $F_{\mathrm{O}}$, the terrestrial biosphere $F_{\mathrm{B}}$, and the stratosphere $F_{\mathrm{S}}$, by input from anthropogenic sources $Q_{\text {Trop }}$, and the radioactive decay $\left({ }^{14} \mathrm{C}\right.$ has a mean lifetime $\left.\lambda^{-1}=8,275 \mathrm{yr}\right)$ as follows

$$
\mathrm{d}\left(N_{\text {trop }}\right) / \mathrm{d} t=F_{\mathrm{O}}+F_{\mathrm{B}}+F_{\mathrm{S}}+Q_{\text {trop }}-\lambda N_{\text {trop }}
$$

Only the global response on the interannual timescale to a major atmospheric perturbation is examined in this study. We can therefore use relatively simple models to determine the respective radiocarbon fluxes. For the ocean, a type of robust Oeschger and Siegenthaler box diffusion model $l^{4.5}$ was adopted using a vertical eddy diffusion coefficient $K=7,685 \mathrm{~m}^{2} \mathrm{yr}^{-1}$ coupled to $7.8 \mathrm{yr}$ residence time of atmospheric $\mathrm{CO}_{2}$ with respect to air/sea gas exchange. The flux $F_{\mathrm{O}}$, calculated according to our tropospheric boundary conditions, matches the integrated oceanic bomb ${ }^{14} \mathrm{C}$ uptake (until 1 January 1974 ) of $300 \times 10^{26}$ atoms (Fig. 2a) derived from oceanic measurements during GEOSECS $^{3}$, and compares well with results of the most recent version of the HILDA ${ }^{17}$ ocean model.

The model biosphere is divided into three boxes where the input carbon is decomposed exponentially with an e-folding constant given by the turnover time $\tau$. Box 1 has a mass of $105 \mathrm{Gt}-\mathrm{C}$ (gigatonnes carbon; $1 \mathrm{Gt}=10^{15} \mathrm{~g}$ ), $\tau=3 \mathrm{yr}$, and accounts for fine roots, twigs and leaves. Box 2 has a mass of $675 \mathrm{Gt}-\mathrm{C}, \tau=27 \mathrm{yr}$, and represents big roots, stems and branches. Boxes 1 and 2 couple directly to the troposphere, and the sum of their input fluxes, determining the net primary productivity, is set to $60 \mathrm{Gt}-\mathrm{C} \mathrm{yr}^{-1}$. Box 3, the 'old carbon reservoir' has a mass of $1,420 \mathrm{Gt}-\mathrm{C}$ and $\tau=375 \mathrm{yr}$. Box 3 contains the slowly decomposing material of boxes 1 and 2 , gets its carbon input equally distributed from these boxes, and is needed to account for the low $\Delta^{14} \mathrm{C}$ values measured in soil organic carbon $^{18}$. These settings correspond to previously published estimates for the terrestrial biosphere ${ }^{19}$. We did not account for fertilisation and destruction fluxes when calculating $F_{\mathrm{B}}$ from the tropospheric boundary conditions.

Our model stratosphere consists of one box with the same $\mathrm{CO}_{2}$ concentration as the model troposphere, and a turnover time of $2.5 \mathrm{yr}$ with respect to the troposphere. The total mass of the stratosphere box corresponds to $15 \%$ of the total atmosphere air mass. $F_{\mathrm{S}}$ was calculated from the bomb input scenario and the measured tropospheric boundary conditions.

The initial conditions in 1945 for all reservoirs were computed starting at preindustrial equilibrium in $\mathrm{AD} 1750$ (atmospheric concentrations: 280 p.p.m.v. $\quad \mathrm{CO}_{2}, \quad \Delta^{14} \mathrm{C}=-4.5 \%$ ). Using observed atmospheric $\mathrm{CO}_{2}$ concentrations ${ }^{8}$ and ${ }^{14} \mathrm{CO}_{2}$ data ${ }^{9}{ }^{12}$ (Fig. $3 b$ ) as prescribed input data in all scenarios, we automatically account for the dilution of ${ }^{14} \mathrm{CO}_{2}$ by input of ${ }^{14} \mathrm{C}$ free carbon from fossil fuel consumption (Suess effect ${ }^{20}$ ). All natural ${ }^{14} \mathrm{C}$ production $\left(P_{\text {nat }}=2.3 \times 10^{26}\right.$ atoms $\mathrm{yr}^{-1}$, assumed to be constant) occurred in the stratosphere.

The anthropogenic input of ${ }^{14} \mathrm{CO}_{2}$ by the nuclear industry, contributing significantly to the tropospheric inventory only from about 1970 onwards, was calculated for different reactor types using the normalized ${ }^{14} \mathrm{CO}_{2}$ emission data per generated electrical energy reported by Bonka ${ }^{21}$ and in UNSCEAR ${ }^{22}$. The latter was estimated for the period of 1970 to 1990 from the installed plants worldwide, assuming a capacity utilization of $60 \%$ for all reactor types. ${ }^{14} \mathrm{CO}_{2}$ emissions from reprocessing plants were also taken from UNSCEAR ${ }^{22}$. The ${ }^{14} \mathrm{CO}_{2}$ release from the nuclear industry in 1990 was estimated to be less than $0.5 \times 10^{26}{ }^{14} \mathrm{C}$-atoms $\mathrm{yr}^{-1}$, increasing almost linearly from 1970 onwards (compare Fig. $2 b$ ).

${ }^{14} \mathrm{C}$ input from the atmospheric bomb tests was estimated based on the compilation of bomb strength datals (Fig. 1b), and, depending on the respective scenario, adjusting the specific ${ }^{14} \mathrm{C}$ production per megatonne (Mt) TNT to the tropospheric and stratospheric observations during the time period of the major ${ }^{14} \mathrm{C}$ rises. The uncertainty of this adjustment is small as total carbon fluxes between the reservoirs, and on the internal circulation dynamics within these reservoirs. 
FIG. 1 a-d, Comparison between results from two ${ }^{14} \mathrm{C}$ model scenarios (dotted lines) and observations (solid lines) in the stratosphere ( $a$ and $c$ ), and in the troposphere ( $b$ and $d$ ). The observed stratospheric inventories were taken from Tans ${ }^{13}$ and Telegadas ${ }^{14}$ (according to Tans ${ }^{13}$, the original observations are corrected by $-20 \%$; a further adjustment of $+3.5 \%$ was made to correct for the NBS oxalic acid standard activity value used by Telegadas ${ }^{14}$ ). Mean tropospheric ${ }^{14} \mathrm{C}$ inventories are calculated from long-term tropospheric observations in both hemispheres ${ }^{9-12}$. For the early period of 1950-59, we use tree ring ${ }^{14} \mathrm{C}$ data ${ }^{33}$. In both scenarios, the stratosphere consists of only one box with an air mass of $15 \%$ of the atmosphere, corresponding to a tropopause level at $13.5 \mathrm{~km}$. In scenario I ( $a$ and $b$ ), the bomb ${ }^{14} \mathrm{C}$ input is estimated using the bomb strength data $(b)$, and the standard ${ }^{14} \mathrm{C}$ yield $P_{\text {stand }}$ of $1.75 \times 10^{26}$ atoms per Mt-TNT (ref. 23). With $P_{\text {stand }}$ the tropospheric and the stratospheric ${ }^{14} \mathrm{CO}_{2}$ levels are overestimated. In scenario II ( $c$ and $d$ ) the bomb ${ }^{14} \mathrm{C}$ input is adjusted to $60 \%$ of $P_{\text {stand }}$. The model matches the observations in the troposphere until about 1963. After that date the decrease in the troposphere is much faster than actually observed. The missing tropospheric ${ }^{14} \mathrm{CO}_{2}$ source needed to adjust model and data results is similar in time-dependence and strength to $25 \%$ of the oceanic or, equivalently, to $80 \%$ of the biospheric net bomb ${ }^{14} \mathrm{C}$ uptake flux (see Fig. $3 e$ and $d$ ).

\section{SCENARIO I}
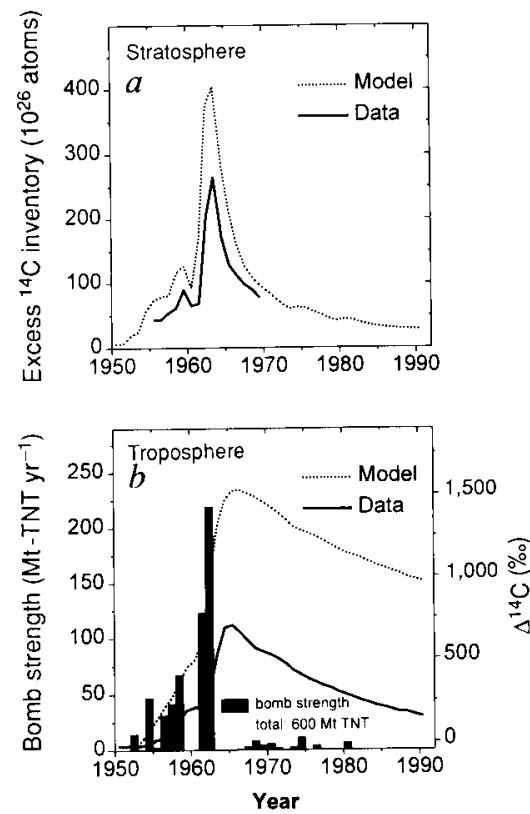

SCENARIO II

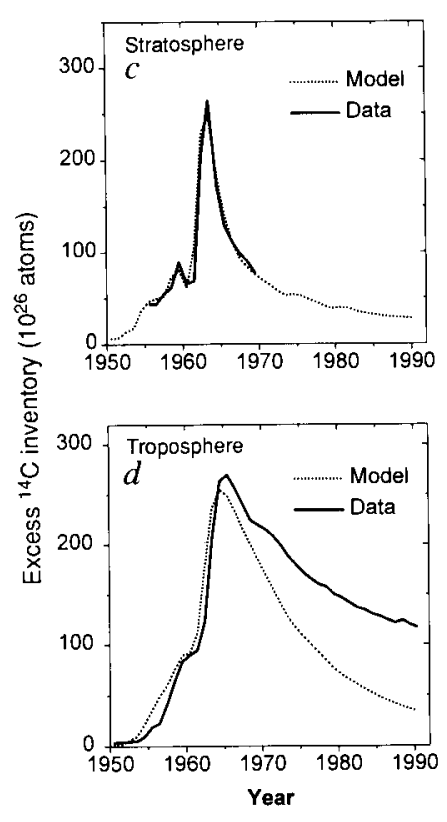

the total bomb ${ }^{14} \mathrm{C}$ uptake by the ocean and the biosphere, compared to the bomb input, is small until 1963. As the observational data in the troposphere show a systematic delay between the date when the stronger bombs were fused, and the date when the respective signal showed up in the troposphere, we introduced all bomb ${ }^{14} \mathrm{C}$ production directly into the stratosphere. The results reported in Fig. $1 a$ and $b$ show clearly that the ${ }^{14} \mathrm{C}$ production calculated with the standard ${ }^{14} \mathrm{C}$ yield $P_{\text {stand }}=$ $1.75 \times 10^{26}$ atoms per Mt-TNT (ref. 23) was overestimated. In fact, estimates of $P_{\text {stand }}$ are in the range $(1-2) \times 10^{26}$ atoms per Mt-TNT) (refs 21, 24).

Figure $l c$ and $d$ (scenario II) shows the results obtained when reducing the value of $P_{\text {stand }}$ by $40 \%$. The model inventory fits well with the data in the stratosphere and in the troposphere until 1963, as long as the bomb production is the dominant flux term. In the post-bomb period, the model troposphere is influenced by a much too strong sink term. The fictive tropospheric source needed to adjust the model and data turns out to be similar in time-dependence and strength to $25 \%$ of the oceanic or, equivalently, to $80 \%$ of the biospheric net bomb ${ }^{14} \mathrm{C}$ uptake flux (Fig. 2b). The magnitude of the missing source can be in error by at most one-third. This is mainly due to the strong constraint on the coupling constants between the reservoirs given by the $>40-\mathrm{yr}$ record of tropospheric ${ }^{14} \mathrm{CO}_{2}$ observations. The strength of the missing source should decrease with an e-folding time similar to the ocean uptake, that is, $\sim 8 \mathrm{yr}$. Neither the nuclear industry nor the natural cosmic ray production can account for this source. The variation of cosmic ray production is $\sim 40 \%$ between solar minimum and solar maximum ${ }^{25}$, and thus at least one order of magnitude too small. The ${ }^{14} \mathrm{C}$ production by nuclear industry is only a few per mil of the needed ${ }^{14} \mathrm{C}$ source in the $1970 \mathrm{~s}$, while increasing instead of declining (Fig. 2b).

Looking for a candidate in the atmosphere itself, we divided the stratosphere into two boxes. The high box contains $<1.5 \%$ of the atmospheric mass (lower boundary corresponding to $25 \mathrm{~km}$ a.s.1.) and has a turnover time $\tau$ of $5 \mathrm{yr}$ exchanging with the low box ( $\tau=2.5 \mathrm{yr}$ with respect to the troposphere). In Fig. $3 a$ and $b$ the results obtained with such a two-box stratosphere (scenario III) are shown. In this scenario, $15 \%$ of the adjusted bomb production (in this case $70 \%$ of $P_{\text {stand }}$ ) is injected into the high stratosphere, the rest into the low stratosphere. Scenario III now leads to a nearly perfect agreement between the model and the observations in the lower stratosphere and in the tropo-
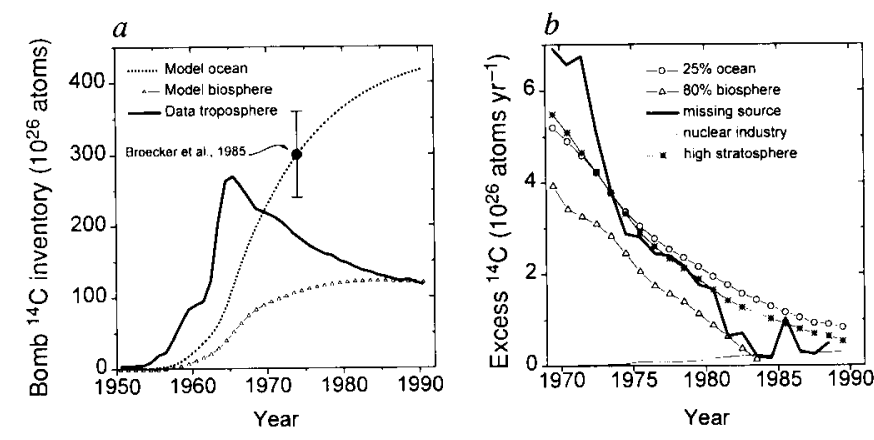

FIG. 2 Bomb ${ }^{14} \mathrm{C}$ inventories (a) and missing source flux (b). $a$, The standard bomb ${ }^{14} \mathrm{C}$ inventories are calculated as the difference to the respective ${ }^{14} \mathrm{C}$ inventory in 1940 . The standard inventories for the ocean (dotted line) and the biosphere $(\triangle)$ are as calculated for scenarios I, II and III with prescribed tropospheric values. The standard ocean bomb ${ }^{14} \mathrm{C}$ inventory on January 1974 matches the value of $300 \times 10^{26}$ atoms (-) given by Broecker et $a .^{3} . b$, The missing ${ }^{14} \mathrm{C}$ flux to the troposphere (6 year running means, thick solid line) is as calculated in scenario II (Fig. 1d). This missing flux is compared to the net supplementary contributions from (1) a high stratosphere ( $\star$, scenario III), (2) a $80 \%$ reduction of the standard biospheric uptake $(\Delta$, scenario IV), and (3) a $25 \%$ reduction of the standard oceanic uptake $(O$, scenario $\mathrm{V})$. In all three cases, the supplementary flux has the right time-dependence and amplitude to account for the missing source (Fig. $3 b, d$ and e). The emission from nuclear installations (thin solid line) is also given for comparison.

sphere. However, scenario III demands very high $\Delta^{14} \mathrm{C}$ values in the remote high stratosphere (Fig. $3 a$ ) which is inconsistent with recent ${ }^{14} \mathrm{CO}_{2}$ observations ${ }^{26}$ up to $30 \mathrm{~km}$ height. Also the old data from Telegadas ${ }^{14}$ obtained in the early 1960 s suggest a $\Delta^{14} \mathrm{C}$ decrease rather than an increase to higher stratospheric levels. Moreover, the observed decrease from intermediate to high stratospheric levels has also been obtained by recent high-resolution stratospheric model calculations ${ }^{27}$. Therefore even a supposed remote stratosphere with still very high ${ }^{14} \mathrm{CO}_{2}$ can most probably not close the bomb ${ }^{14} \mathrm{C}$ budget.

On the other hand, assuming almost no bomb ${ }^{14} \mathrm{C}$ uptake by the terrestrial biosphere (scenario IV, Fig. $3 c$ and $d$ ) would also match the bomb radiocarbon constraints. In our scenario this reduced uptake is simply obtained by multiplying the standard 
FIG. 3 Comparison between observed and calculated $\Delta^{14} \mathrm{C}$ values in the troposphere $(b, d, e)$ and in the two- and one-box stratosphere ( $a$ and $c$ respectively). ${ }^{14} \mathrm{C}$. results of stratospheric sampling in 1989 (ref. 26) are included in a. $\left(\Delta^{14} \mathrm{C}\right.$ concentrations are per mil deviations from NBS oxalic acid activity corrected for decay ${ }^{34}$ ). In scenario III ( $a$ and $b$ ) bomb ${ }^{14} \mathrm{C}$ input is adjusted to $70 \%$ of $P_{\text {stand }}$. The stratosphere is subdivided into two boxes, $85 \%$ of the bomb ${ }^{14} \mathrm{C}$ input is introduced into the lower stratosphere, and $15 \%$ into the remote high stratosphere. The model results agree well with the atmospheric observations in the troposphere and in the lower stratosphere $190 \%$ of stratospheric air mass, $13.5-25 \mathrm{~km}$ height). The stratospheric observations, however, indicate that, even in the early 1990 s, the modelled upper stratospheric $\Delta^{14} \mathrm{C}$ is still $\sim 2$ times too high. In scenario IV (c and $d$ ) and $V(e)$, as in scenario II (Fig. $1 \mathrm{c}$ and $d$ ), bomb ${ }^{14} \mathrm{C}$ input is adjusted to $60 \%$ of $P_{\text {stand }}$ and introduced into the one-box stratosphere. In scenario IV, the bomb ${ }^{14} \mathrm{C}$ uptake by the biosphere has been reduced by $80 \%$, and in scenario $\mathrm{V}$, bomb ${ }^{14} \mathrm{C}$ uptake by the oceans has been reduced by $25 \%$ with respect to the standard case given in scenario II. Scenarios IV and $\mathrm{V}$ satisfactorily match the ${ }^{14} \mathrm{CO}_{2}$ observations, both in

uptake of the biosphere by 0.2 . In reality, such a strong reduction is only achieved if, for example, the net primary productivity is reduced by a factor of 5 and the reservoir sizes are modified accordingly. This, however, would so seriously contradict our understanding of mass, cycling and turnover times in the biosphere ${ }^{28}$ that scenario IV appears highly improbable.

The most tempting solution to the problem would be an $\sim 25 \%$ reduction of the ${ }^{14} \mathrm{C}$ uptake by the oceans (scenario $\mathrm{V}$, Fig. $3 \mathrm{c}$ and $e$ ) leading to an oceanic bomb ${ }^{14} \mathrm{C}$ inventory reduced by the same amount. This means only a correction to known processes (for example, gas exchange rate and vertical mixing) rather than introducing, for example, still unconsidered sub-reservoirs as in the biospheric or stratospheric scenarios. However, a $25 \%$ reduction of the bomb ${ }^{14} \mathrm{C}$ inventory of the oceans lies outside the error bars generally accepted for this quantity $(20 \%$, ref. 3$)$. The contradiction gets even larger when taking into account the very recent upward revision of the oceanic bomb ${ }^{14} \mathrm{C}$ inventory, evaluated on the basis of more observations and an improved estimation of the pre-bomb natural oceanic radiocarbon distribution ${ }^{29}$. This problem needs to be resolved.

A $25 \%$ reduction of bomb ${ }^{14} \mathrm{C}$ uptake by the ocean models would have significant implications for our understanding of the global carbon cycle. First, the radiocarbon-derived $\mathrm{CO}_{2}$ gas exchange coefficient has to be reduced by the same amount, then being almost in agreement with the estimates of Liss and Merlivat ${ }^{30}$, which were based on direct measurements in wind tunnels and over lakes and open ocean ${ }^{31}$. Second, if we believe the ${ }^{14} \mathrm{C}$ observations in surface water performed during the past 30 years, the estimated bomb ${ }^{14} \mathrm{C}$ penetration depth ${ }^{32}$ has to be reduced. Furthermore, if it is assumed that the $\mathrm{CO}_{2}$ uptake by the oceans scales directly with the bomb ${ }^{14} \mathrm{C}$ penetration depth ${ }^{16}$, a downward revision of the latter would imply a corresponding reduction by $\sim 25 \%$ of the inferred oceanic sink for anthropogenic $\mathrm{CO}_{2}$.

Received 17 December 1993; accepted 10 June 1994.

1. Stuiver, M. J. geophys. Res. 85, 2711-2718 (1980).
SCENARIO IV

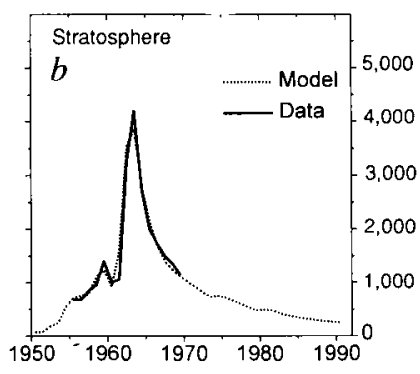

SCENARIO $\mathrm{V}$
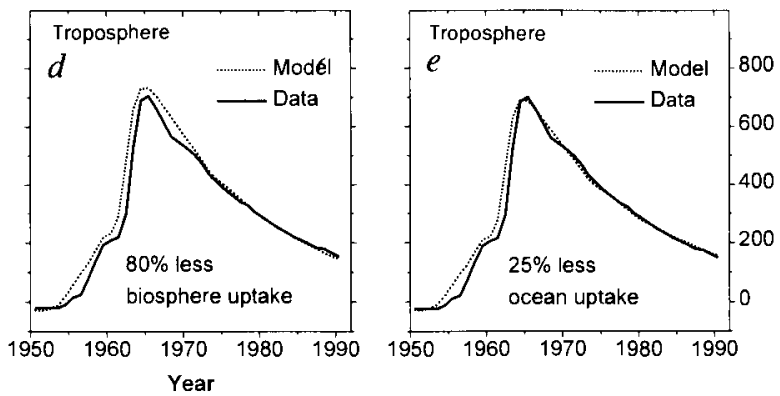

the troposphere as well as in the one-box stratosphere (the stratospheric model results of scenario $V$ are indistinguishable from those of scenario IV). However, neither of these scenarios corresponds to our present understanding of the carbon cycle.

2. Stuiver, M., Oestlund, H. G. \& McConnaughey, T. A. in SCOPE 16, Carbon Cycle Modelling (ed. Bolin, B.) 201-221 (Wiley, New York, 1981).

3. Broecker, W. S., Peng, T. H., Östlund, G. \& Stuiver, M. J. geophys. Res. 90, 6953-6970 (1985).

4. Oeschger,H., Siegenthaler, U., Schotterer, U. \& Gugelmann, A. Tellus 27, 168-192 (1975).

5. Siegenthaler, U. J. geophys. Res. 88, 3599-3608 (1983).

6. Toggweiler, J. R., Dixon, K. \& Bryan, K. J. geophys. Res. 94, 8217-8242 (1989)

7. Maier-Reimer, E. Globl Biogeochem. Cycles 7, 645-677 (1993).

8. Keeling, C. D. \& Whorf, T. P. in Trends 90 (eds Boden, T. A., Kanciruk, P. \& Farrell, M. P.) 8-9 (Oak Ridge natn. Lab., Oak Ridge, 1990).

9. Levin, I. et al. Radiocarbon 27, 1-19 (1985).

10. Levin, I., Kromer, B., Wagenbach, D. \& Münnich, K. O. Tellus 39B, 89-95 (1987).

11. Manning, M. et al. Radiocarbon 32, 37-58 (1990).

12. Levin, I. et at. in Radiocarbon After Four Decades: an Interdisciplinary Perspective (eds Taylor, R. E., Long, A. \& Kra, R.) 503-518 (Springer, New York, 1992)

13. Tans, P. P. in SCOPE 16, Carbon Cycle Modelling (ed. Bolin, B.) 131-157 (Wiley, New York, 1981).

14. Telegadas, K. in Report HASL 243 12-187 (N.T.I.S., Soringfield, Virginia, 1971)

15. Rath, H. K. thesis, Univ. Heidelberg (1988).

16. Siegenthaler, U. \& Sarmiento, G. Nature 365, 119-125 (1993).

17. Siegenthaler, U. \& Joos, F. Tellus 44B, 186-207 (1992).

18. Harrison, K., Broecker, W. S. \& Bonani, G., Globl Biogeochem. Cycles 7, 69-80 (1993).

19. Siegenthaler, U. \& Oeschger, H. Tellus 398, 140-154 (1987).

20. Suess, H. E. Science 122, 415-417 (1955).

21. Bonka, $\mathrm{H}$. in Strahlenschutzprobleme im Zusammenhang mit der verwendung von Tritium und Kohlenstoff-14 und ihren verbindungen (eds Stieve, F. E. \& Kirstner, G.) 17-26 (Dietrich Reimer, Berlin, 1980).

22. UNSCEAR 1993 Report to the General Assembly (United Nations Publication, Sales No. E.94.IX.2).

23. UNSCEAR 1982 Report to the General Assembly (United Nations Publication, Sales No. E.82.1X.8).

24. Machta, L., List, R. J. \& Telegadas, K. in Congress of the U.S., Hearing before Subcommittee in Research, Development and Radiation of the Joint Committee of Atomic Energy, $88^{\text {th }}$

25. Damon, P. \& Sternberg, R. Radiocarbon 31, 697-703 (1989).

26. Nakamura, T. et al. Radiocarbon 34, 745-752 (1992).

27. Rasch, P. J., Tie, X. X., Boville, B. A. \& Williamson, D. L. J. geophys. Res. 99, 999-1017 (1994).

28. Goudriaan, J. J. Expl. Bot. 43, 1111-1119 (1992).

29. Peng, T. H. \& Broecker, W. S. in Abstr. 4th international $\mathrm{CO}_{2}$ Conf. (eds Lambert, G. \& Merlivat, L.) 214 (WMO-GAW-Report No. 89, WMO/TD-NO 561, Geneva, 1993).

30. Liss, P. \& Merlivat, L. in The Role of Air.Sea Exchange in Geochemical Cycling (ed. BuatMénard, P.) 113-127 (Reidel, Dordrecht, 1986).

31. Watson, A. in The Global Carbon Cycle (ed. Heimann, M.) 397-412 (Springer, Heidelberg, 1993).

32. Broecker, W. S., Peng, T. H. \& Engh, R. Radiocarbon 22, 565-598 (1980).

33. Stuiver, M. \& Quay, P. Earth planet. Sci. Lett. s3, 349-362 (1981)

34. Stuiver, M. \& Polach, H. A. Radiocarbon 19, 355-363 (1977).

ACKNOWLEDGEMENTS. This Letter is dedicated to our teacher $K$. O. Münnich. We thank $F$. Joos for providing ${ }^{14} \mathrm{C}$ flux data from the HILDA model, and B. Bolin, I. Enting, P. Tfans and W. Weiss for suggestions and comments. This work was supported by the German Minister of Science and Technology. Bonn, and the Commission of the EU, Brussels. 